\title{
Enhancement of Surface Roughness and Corrosion Resistance of Wedmed Al 7075 Alloy
}

\author{
B Rajnaveen, G Rambabu, D Balaji Naik, Abdul SilarBabu
}

\begin{abstract}
An alloy of Aluminium has good properties and strong would be ideal for many applications. Among all the series of aluminium alloys, Al 7075 is extensively used in aircraft structures, gear shafts, and automotive industry because of its high strength and good corrosion resistance. The machining of $\mathrm{Al}$ 7075 can be done under annealed conditions and lubricants are used for operations. In the present work, Al 7075 was machined by using Wire Electric Discharge Machine (WEDM) and investigated the effect of operating parameters on reponses. The surface roughness and corrosion resistance are considered as responses. The operating parameters of WEDM considered in this work are pulse ON time, pulse OFF time, wire feed and servo voltage. Experiments were conducted according to the Taguchi's design of orthogonal array $\operatorname{L18}\left(2^{1} \times 3^{3}\right)$. The values of surface roughness and corrosion pit potentials were observed for each experiment to understand the relationship. Multi-objective optimization for these process parameters has been carried out by Grey Relation Analysis (GRA). From this technique, the optimum combination of process parameters are obtained and corresponding values of surface roughness and corrosion pit potentials are found out. To validate the response table for grey relation grade obtained from GRA, Taguchi analysis was carried out which shows that the pulse on time is the most influencing parameter followed by pulse off time, wire feed and servo voltage.
\end{abstract}

Keywords: Al 7075 alloy, surface roughness, corrosion resistance, Taguchi design, Grey Relational Analysis

\section{INTRODUCTION}

Wire Electrical Discharge Machining (WEDM) is an electro-thermal manufacturing method that utilizes electricity to accurately cut any conductive material with a thin, electrically charged wire as an electrode. Wire EDM is a non-contact machining process where the tool is separated from the workpiece with a dielectric solution of de-ionized water to continuously tool and flush the machining area. As the wire approaches the workpiece, electrical charge

Manuscript published on November 30, 2019.

* Correspondence Author

B Rajnaveen*, Mechanical Engineering department, Andhra University, Vishakapatnam, India. Email: rajnaveenb@gmail.com

Dr G Rambabu, Mechanical Engineering department, Andhra University, Vishakapatnam, India. Email: govada_rambabu@yahoo.com

D Balaji Naik, Mechanical Engineering department, Andhra University, Vishakapatnam, India. Email: balajinayak278@gmail.com

Abdul SilarBabu, Mechanical Engineering department, Andhra University, Vishakapatnam, India. Email: rajasilar@gmail.com

(C) The Authors. Published by Blue Eyes Intelligence Engineering and Sciences Publication (BEIESP). This is an open access article under the CC-BY-NC-ND license

(http://creativecommons.org/licenses/by-nc-nd/4.0/) attraction produces a controlled spark, melting and vaporizing microscopic material particles. Therefore, the result is a product with an excellent surface finish. But WEDM is a machining method controlled by various interrelated complex parameters like discharge current, pulse ON time, pulse OFF time wire feed, servo voltage, etc. Any slight variation in one will affect performance measures of machining, such as surface roughness and material removal rate etc. However, machining of hard materials like aluminium alloys is very difficult with the conventional machining process. Therefore, many researchers use non-conventional wire electrical discharge machining process to enhance the material properties of aluminium alloys. K Mouralov et.al [1] analyzed the surface morphology and topography of pure aluminium after machined using WEDM. The damping behavior of WEDMed aluminium A356.2 alloy was evaluated and optimized by D S Prasad et.al [2]. Machining of aluminium 7075 with the highest accuracy is possible by using the WEDM process [3]. R Soundararajan et.al [4] investigated the MRR and surface roughness of squeeze cast A413 alloy on WEDM. The optimal condition for machining process was carried out by response surface methodology. V Chenga Reddy et.al [5] studied the effect of various process parameters of WEDM like pulse ON time, pulse OFF time, current, wire tension, flushing pressure for aluminium HE30 by using Grey relational analysis. Whereas, Ravindranadh [6] showed pulse ON time, peak current and spark voltage were significant variables to grey relational grade for WEDMed Al6063 alloy. G Selvakumar et.al [7] conducted experiments on Al5083 alloy by using WEDM and optimized the process parameters by Pareto Optimality approach. Brajesh Kumar and Sanjay Agarwal [8] observed that the discharge current is the most influencing parameter while optimizing machining parameters in WEDM of AISI D3 steel. PS Rao [9] attempted to study the effect of wire EDM parameters on aluminium alloy and performed parametric analysis on surface roughness and material removal rate by Taguchi method. A unique overall and adaptable tool for design and automation are provided by numerical optimization methods [10]. In the process of establishing the Grey system theory, Professor Julong Deng [11] discovered and extracted the Grey Relational Analysis to optimize the statistical problems. Grey Relational Analysis provides an efficient solution to the uncertainty, multi-input and discrete data problems [12]. Moreover, it gives the relationship between the input parameters and responses of any manufacturing process. 
Therefore, J B Saedon et.al [13] uses Grey relational analysis to conduct multi-objective optimization of titanium alloy along with Taguchi technique and adequacy of the analysis was tested by using Analysis of variance (ANOVA). Bijo Mathew et.al [14] also used Taguchi based grey relational analysis to optimize the process parameters of WEDM on AISI 304. Taguchi based grey relational analysis was employed by $\mathrm{Z}$ A Khan et.al [15] to optimize the multi-responses like surface roughness and kerf width under the effect of current, pulse ON time and pulse OFF time. This study concludes that Pulse ON time is the most influencing factor for both surface roughness and kerf width. M Durairaj et.al [16] also takes surface roughness and kerf width as responses of WEDM and analyze using the single objective Taguchi optimization method along with multi-objective grey relation grade for SS304 material.

It seems from the above-mentioned literature, most of the published research work concentrated on optimizing the process parameters like surface roughness, MRR, and kerf width on different series of aluminium alloys. And the optimization is done by Taguchi based grey relational analysis. But, no work has reported the effect of corrosion resistance of $\mathrm{Al} 7075$ alloy machined by using WEDM under different input parameter conditions. As Al 7075 alloy shows good corrosion resistance, it is very important to understand the effect and optimize the corrosion resistance property along with surface roughness. Therefore, in this work surface roughness and corrosion resistance were taken as responses and pulse OFF time, pulse ON time servo voltage, wire feed was taken as input parameters. The experiments were planned according to the Taguchi based design of experiments [17]. Grey relational analysis [18] was used to optimize the process parameters of WEDM.

\section{EXPERIMENTAL SETUP}

The material selected in the present work is low-temperature heat-treated and artificially aged Al 7075 alloy. The chemical composition of $\mathrm{Al} 7075$ was shown in Table I and physical properties like tensile strength, yield strength, thermal conductivity, and hardness are 572.3 MPa, $503.3 \mathrm{MPa}, 130 \mathrm{~W} / \mathrm{m}-\mathrm{K}$, and $150 \mathrm{BHN}$ respectively [24]. A rectangular block of dimensions 20 x15 x $200 \mathrm{~mm}$ was taken and machined using ELECTRONICA HITECH High Precision Wire Electrical Discharge Machine which is shown in Fig. 1. It is a 5 axes servo drive front loading machine and has table moving structure with $400 \times 300 \times 250 \mathrm{~mm}$ travel in $\mathrm{X}, \mathrm{Y}$ and $\mathrm{Z}$ axes respectively. According to the Taguchi design of experiments, a total of 18 experiments were conducted by varying process parameters and samples are shown in Fig. 2. For each experiment, a length of $10 \mathrm{~mm}$ was cut by $0.25 \mathrm{~mm}$ diameter brass wire and surface roughness is measured on the machined surface by stylus type Mitutoyo SurftestSJ-301 as shown in Fig. 3. After measuring Surface roughness samples were taken to corrosion resistance test. Potentiodynamic polarization tests were conducted to study the pitting corrosion behavior of machined surfaces by using the GillAC basic electrochemical system (Fig. 4). The detection of electrochemical parameters identifies the corrosion factors of a material. A reliable and well-functioned corrosion system required to achieve this. Electrochemical techniques provide a quick and relatively inexpensive method to obtain electrochemical properties of a material. These methods are mainly based on the capacity to detect a metal's corrosion by monitoring the charging-transfer process reaction to a controlled electrochemical disruption. The corrosion characteristics of a test specimen can be predicted from the polarization scan produced by a potentiostat. A polarization scan enables the kinetic and corrosion parameters of a metal substratum to be extrapolated. A charge transfer and the motion of reactants can limit the oxidation or reduction of an electro-active species during the scan. These factors are all encapsulated by the polarization scan; therefore having a system that produces a reliable and repeatable polarization scan across multiple cycles is of great importance. In this experiment, corrosion of the samples was quantified via potentiodynamic polarization technique employing three-electrode configuration, consist of reference, counter and the working electrode. Al 7075 alloy was used as a working electrode. Saturated Calomel Electrode (SCE) and platinum electrode were used as reference and counter electrode respectively. All experiments were conducted in a $3.5 \% \mathrm{NaCl}$ solution with $\mathrm{pH}$ adjusted to 10 . The potential scan rate was set up as $0.167 \mathrm{mV} / \mathrm{s}$ with an initial potential of $-0.25 \mathrm{~V}$ SCE to the final potential of pitting. The samples are studied at a $1 \mathrm{~cm}^{2}$ exposure area. The potential at which current increases drastically was considered as critical pitting potential $\left(E_{\text {pit }}\right)$. Specimens with comparatively more positive potential were regarded to be those with better resistance to pitting corrosion.

Table I: Chemical composition of Al7075 alloy [24]

\begin{tabular}{|c|c|c|c|c|c|c|c|c|c|}
\hline $\begin{array}{c}\text { Constit } \\
\text { uent }\end{array}$ & $\mathrm{Si}$ & $\mathbf{F e}$ & $\mathbf{C u}$ & $\begin{array}{c}\mathbf{M} \\
\mathbf{n}\end{array}$ & $\begin{array}{c}\mathbf{M} \\
\mathbf{g}\end{array}$ & $\mathrm{Cr}$ & $\mathrm{Zn}$ & $\mathbf{T i}$ & Al \\
\hline $\begin{array}{c}\% \\
\text { compo } \\
\text { sition }\end{array}$ & 0.4 & 0.5 & 1.2 & 0.3 & $\begin{array}{l}2.1 \\
-2 . \\
9\end{array}$ & $\begin{array}{l}0.18- \\
0.28\end{array}$ & $\begin{array}{l}5.1 \\
-6 . \\
1\end{array}$ & 0.2 & $\begin{array}{l}87.2- \\
91.4\end{array}$ \\
\hline
\end{tabular}

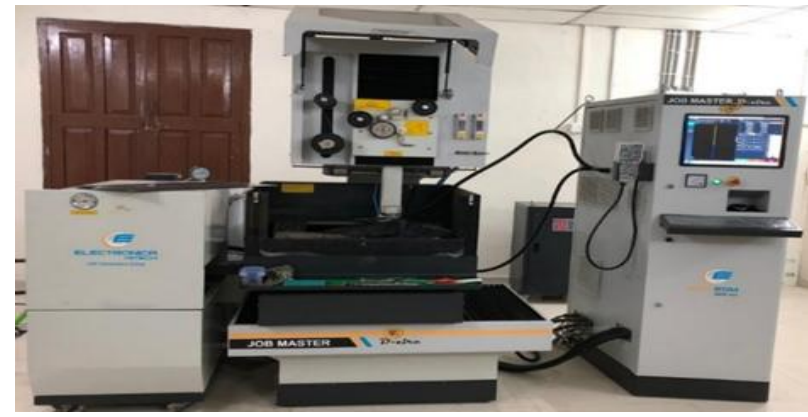

Fig. 1: WEDM Machine setup

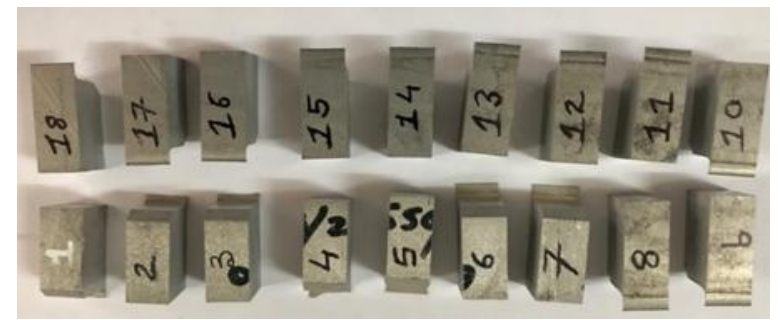

Fig. 2: WEDM machined samples 


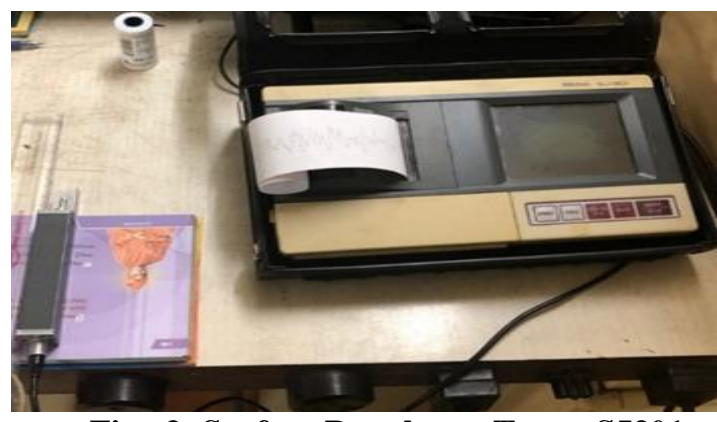

Fig. 3: Surface Roughness Tester SJ301

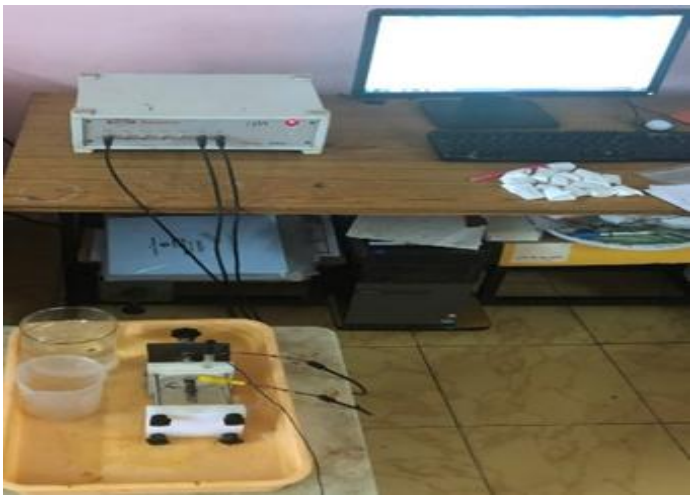

Fig. 4: Corrosion test setup

\section{A. Design of Experiments:}

Taguchi's technique provides a solid design in which the process not only remains within the requirements but is always focused on the goal. This method follows an approach which minimizes the impact of variation on the response, neutralizes the noise and thus ensures process mean is at the target. Taguchi's design uses an orthogonal array to reach the optimum with minimum trails at minimum cost. We select the suitable orthogonal array by referring standard orthogonal array table is L18 $\left(2^{1} \times 3^{3}\right)$. Based on the machining conditions the process parameters and their levels selected is listed in Table II.

Table II: Process parameter and their levels

\begin{tabular}{|c|c|c|c|c|c|}
\hline Parameter & Symbol & Unit & Level 1 & $\begin{array}{c}\text { Level } \\
\mathbf{2}\end{array}$ & Level 3 \\
\hline $\begin{array}{c}\text { Pulse ON } \\
\text { time }\end{array}$ & TON & $\mu \mathrm{sec}$ & 115 & 120 & 125 \\
\hline $\begin{array}{c}\text { Pulse OFF } \\
\text { time }\end{array}$ & TOFF & $\mu \mathrm{sec}$ & 57 & 60 & 63 \\
\hline Wire Feed & WF & $\mathrm{mm} / \mathrm{min}$ & 2 & 4 & 5 \\
\hline $\begin{array}{c}\text { Servo } \\
\text { Voltage }\end{array}$ & SV & volts & 20 & 25 & - \\
\hline
\end{tabular}

\section{RESUlts AND DISCUSSIONS}

The objective of this parameter design is to conduct experiments and identify the optimal settings of design parameters that improve the performance characteristics and reduce the sensitivity of engineering design to the source of variation. The desired combination of process parameters and its corresponding corrosion pit potential $(\mathrm{mV})$ and surface roughness is given in Table III.

Table III: Process Parameters and Experimental Results

\begin{tabular}{|c|c|c|c|c|c|c|}
\hline \multirow{2}{*}{$\begin{array}{c}\text { Exp. } \\
\text { No }\end{array}$} & \multicolumn{4}{|c|}{ Process Parameters } & \multirow{2}{*}{$\begin{array}{c}\text { Surface } \\
\text { Roughnes } \\
\text { s (SR) }\end{array}$} & \multirow[b]{2}{*}{$\begin{array}{c}\text { Corrosio } \\
\text { n Pit } \\
\text { Potential } \\
\text { (CPP) in } \\
\text { mV }\end{array}$} \\
\hline & SV & TON & TOFF & WF & & \\
\hline 1 & 20 & 115 & 57 & 2 & 4.44 & -762.58 \\
\hline
\end{tabular}

\begin{tabular}{|l|l|l|l|l|l|l|}
\hline 2 & 20 & 115 & 60 & 4 & 4.17 & -894.19 \\
\hline 3 & 20 & 115 & 63 & 5 & 4.26 & -784.32 \\
\hline 4 & 20 & 120 & 57 & 2 & 5.49 & -503.33 \\
\hline 5 & 20 & 120 & 60 & 4 & 4.85 & -714.44 \\
\hline 6 & 20 & 120 & 63 & 5 & 4.92 & -680.44 \\
\hline 7 & 20 & 125 & 57 & 4 & 4.82 & -719.96 \\
\hline 8 & 20 & 125 & 60 & 5 & 4.66 & -733.94 \\
\hline 9 & 20 & 125 & 63 & 2 & 4.87 & -703.98 \\
\hline 10 & 25 & 115 & 57 & 5 & 4.26 & -777.33 \\
\hline 11 & 25 & 115 & 60 & 2 & 4.21 & -787.38 \\
\hline 12 & 25 & 115 & 63 & 4 & 4.75 & -732.31 \\
\hline 13 & 25 & 120 & 57 & 4 & 4.57 & -742.78 \\
\hline 14 & 25 & 120 & 63 & 5 & 4.89 & -626.09 \\
\hline 15 & 25 & 120 & 60 & 2 & 4.46 & -756.09 \\
\hline 16 & 25 & 125 & 57 & 5 & 5.3 & -614.59 \\
\hline 17 & 25 & 125 & 60 & 2 & 4.65 & -736.91 \\
\hline 18 & 25 & 125 & 63 & 4 & 4.41 & -767.27 \\
\hline
\end{tabular}

From the above table, it was observed that pitting potential values decreases with an increase in surface roughness. The grooves trap the corrosion products on the rougher surfaces, resulting in the more pitting. In smooth surface, the frequency of metastable pit site is reduced and consequently, the corrosion rate is decreased [19]. This is because of the formation of a passive film called recast layer [20] on the machined surface. In WEDM, due to the high-temperature gradient, a small amount of material is melted and evaporated at the electrode and workpiece, and the oxides and carbides are formed results a recast layer on the surface [21]. When the material has the ability to form a recast layer, the smooth surface has fewer places for pit nucleation. The formation of nucleation occurrence on the rougher surface will result in the propagation of pits and thus corrosion [22]. Hence, rougher metal surfaces have reduced pitting potentials because, by growing the roughness, less-open pit sites are preserved as metastable pits during the early phases of developments.

\section{A. Multi-objective Optimization: Grey Relational Analysis:}

Many real-world problems involve the optimization of two or more objectives. One of the mathematical approach called Grey Relation Analysis (GRA) is applied by several researchers to optimize control parameters having multi-responses through grey relation grade. In fact, GRA is a test of the absolute value of the information difference between sequences and could be used to assess the approximate correlation between the sequences [23]. The following steps have been carried out to optimize the WEDM operation with multiple process response characteristics.

Step 1: Pre-Processing data: The obtained process responses are pre-processes depending upon the quality characteristics of the original data.

Step 2: Sequencing Deviation: Deviation sequencing is calculated for the obtained pre-processing data by considering ideal value 1 .

Step 3: Grey Relational co-efficient: In the next step, the Grey Relational co-efficient is calculated individually to represent the relationship between the desired and actual data for all the data obtained from the sequencing deviation.

Step 4: Grey Relational Grade: From the obtained coefficient, the grey relational grade is calculated to see the best process sequence. Higher grey relational grade means that the corresponding parameter combination is closer to the optimal. 
Enhancement of Surface Roughness and Corrosion Resistance of Wedmed Al 7075 Alloy

Step 5: ANOVA for Grey Relational Grade: In the final step the obtained grey relation grade has been analysed by using ANOVA to obtain the optimal process parameter level.

Now, the above-mentioned steps from 1 to 4 was done in MS Excel by appropriate formulas taken from the grey relational theory [18] and are shown in Table IV. The final step i.e. ANOVA for Grey Relation Grade was given in Table V.

Table IV. Grey Relational Analysis from step 1 to step 4

\begin{tabular}{|c|c|c|c|c|c|c|c|}
\hline \multirow{2}{*}{$\begin{array}{c}\text { Exp } \\
\text { No }\end{array}$} & \multicolumn{2}{|c|}{$\begin{array}{c}\text { Pre Data } \\
\text { Processing }\end{array}$} & \multicolumn{2}{c|}{$\begin{array}{c}\text { Deviation } \\
\text { Sequence }\end{array}$} & \multicolumn{2}{c|}{$\begin{array}{c}\text { Grey } \\
\text { Relation } \\
\text { Coefficients }\end{array}$} & \multirow{2}{*}{$\begin{array}{c}\text { Grey } \\
\text { Relationa } \\
\text { I Grade }\end{array}$} \\
\cline { 2 - 6 } & SR & CPP & SR & CPP & SR & CPP & \\
\hline 1 & 0.873 & 0.884 & 0.127 & 0.116 & 0.797 & 0.812 & 0.457 \\
\hline 2 & 0.775 & 0.876 & 0.225 & 0.124 & 0.689 & 0.801 & 0.407 \\
\hline 3 & 0.686 & 1.000 & 0.314 & 0.000 & 0.614 & 1.000 & 0.307 \\
\hline 4 & 0.003 & 0.000 & 0.997 & 1.000 & 0.334 & 0.333 & 0.667 \\
\hline 5 & 0.527 & 0.877 & 0.473 & 0.123 & 0.514 & 0.803 & 0.318 \\
\hline 6 & 0.057 & 0.790 & 0.943 & 0.210 & 0.347 & 0.704 & 0.278 \\
\hline 7 & 0.463 & 0.974 & 0.537 & 0.026 & 0.482 & 0.951 & 0.254 \\
\hline 8 & 0.140 & 0.849 & 0.860 & 0.151 & 0.368 & 0.768 & 0.259 \\
\hline 9 & 0.654 & 0.903 & 0.346 & 0.097 & 0.591 & 0.837 & 0.344 \\
\hline 10 & 0.638 & 0.658 & 0.362 & 0.342 & 0.580 & 0.594 & 0.461 \\
\hline 11 & 1.000 & 0.525 & 0.000 & 0.475 & 1.000 & 0.513 & 0.738 \\
\hline 12 & 0.911 & 0.935 & 0.089 & 0.065 & 0.849 & 0.885 & 0.457 \\
\hline 13 & 0.190 & 0.056 & 0.810 & 0.944 & 0.382 & 0.346 & 0.663 \\
\hline 14 & 0.216 & 0.043 & 0.784 & 0.957 & 0.389 & 0.343 & 0.673 \\
\hline 15 & 0.619 & 0.019 & 0.381 & 0.981 & 0.568 & 0.338 & 0.774 \\
\hline 16 & 0.000 & 0.470 & 1.000 & 0.530 & 0.333 & 0.485 & 0.432 \\
\hline 17 & 0.683 & 0.561 & 0.317 & 0.439 & 0.612 & 0.533 & 0.525 \\
\hline 18 & 0.378 & 0.924 & 0.622 & 0.076 & 0.446 & 0.868 & 0.261 \\
\hline
\end{tabular}

From Table IV, the higher grey relational grade is observed as 0.774 and corresponding experiment data is said to be optimal. The input parameters under this optimal conditions are $\mathrm{SV}=25 \mathrm{~V}, \mathrm{TON}=120 \mu \mathrm{sec}, \mathrm{TOFF}=60 \mu \mathrm{sec}, \mathrm{WF}=2$ $\mathrm{mm} / \mathrm{sec}$. After getting the optimal conditions for the input parameter for surface roughness and pitting potentials, ANOVA for Grey relational grade was carried out in Minitab to see the most influencing parameter for optimal condition. Table 5 depicts that all the four parameters i.e., SV, TON, TOFF, WF are influences but the most influencing parameter is TON. Taguchi analysis was also carried out to validate the response table for Grey Relational Grade under larger is the better condition which is shown in Table VI. From this table, it is noticed that TON gets rank 1 (i.e., most influencing parameter) followed by TOFF, WF and SV. Fig. 5 shows the main effect plot for a grey relational grade.

Table V. Step 5: Analysis of Variance for Grey Relational Grade

\begin{tabular}{|c|c|c|c|c|c|}
\hline Source & DF & Adj SS & Adj MS & F-Value & P-Value \\
\hline SV & 1 & 0.03931 & 0.039311 & 7.78 & 0.019 \\
\hline TON & 2 & 0.29043 & 0.145217 & 28.75 & 0 \\
\hline TOFF & 2 & 0.0546 & 0.0273 & 5.41 & 0.026 \\
\hline WF & 2 & 0.04627 & 0.023136 & 4.58 & 0.039 \\
\hline Error & 10 & 0.05051 & 0.005051 & & \\
\hline Total & 17 & 0.48112 & & & \\
\hline
\end{tabular}

Table VI. Response table for means

\begin{tabular}{|c|c|c|c|c|}
\hline Level & SV & TON & TOFF & WF \\
\hline $\mathbf{1}$ & 0.6525 & 0.7612 & 0.5359 & 0.6056 \\
\hline
\end{tabular}

Retrieval Number: C5883098319/2019@BEIESP

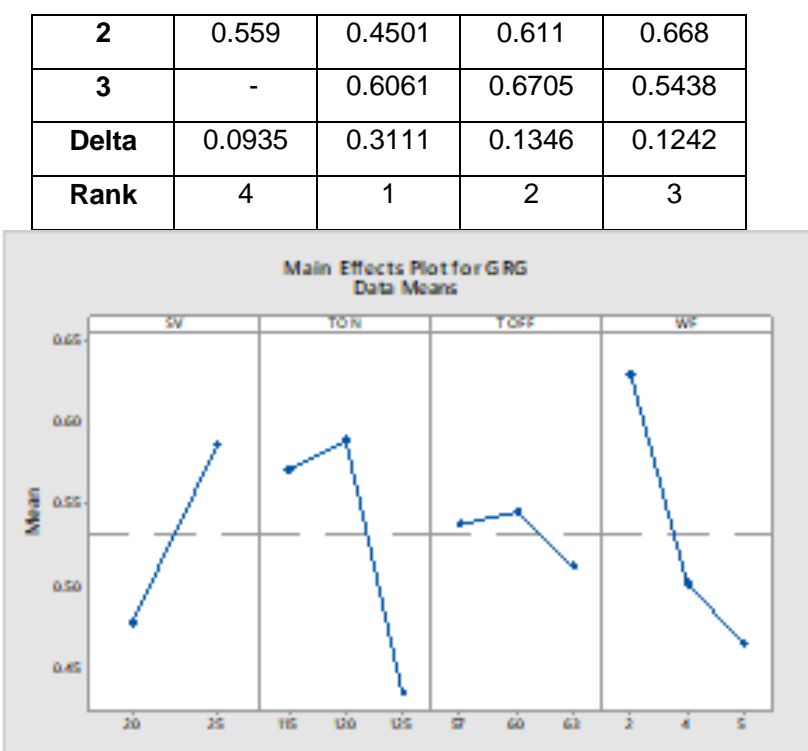

Fig. 5. Main effect plot for grey relational grade

\section{CONCLUSIONS}

In the present work, Grey-Taguchi technique was successfully implemented for converting multi-objective criterion into a single objective and the results obtained by grey-Taguchi analysis showed the better surface roughness and corrosion resistance.

The following observation were made thereby concludes that

1) The optimized process parameters are Servo Voltage at $25 \mathrm{~V}$, pulse $\mathrm{ON}$ time at $120 \mu \mathrm{sec}$, pulse OFF time at $60 \mu \mathrm{sec}$ and Wire Feed at $2 \mathrm{~mm} / \mathrm{sec}$ for both surface roughness and pitting potentials.

2) The Analysis of variance resulted that the pulse ON time has a major influence on responses. Taguchi analysis validates this results that the most influencing parameter is pulse ON time followed by pulse OFF time, wire feed and servo voltage.

3) From the experimental study, it was also observed that rougher surfaces cause more pitting potentials and smooth surfaces have less pit-ting potentials.

\section{APPENDIX: NOMENCLATURE}

$\begin{array}{ll}\text { TON } & \text { : Pulse ON Time } \\ \text { TOFF } & \text { : Pulse OFF Time } \\ \text { WF } & \text { : Wire Feed } \\ S V & \text { : Servo Voltage } \\ \text { SR } & \text { : Surface Roughness } \\ \text { CPP } & \text { : Corrosion Pit Potential } \\ \text { Adj SS } & \text { : Adjusted Sum of Squares } \\ \text { Adj MS } & \text { : Adjusted Mean Squares } \\ \text { GRG } & \text { : Grey Relational Grade. }\end{array}$

\section{ACKNOWLEDGMENT}

This work was supported by the Department of Metallurgical Engineering, Andhra University.

Published By: Blue Eyes Intelligence Engineering \& Sciences Publication 


\section{REFERENCES}

1. Mouralova, K., Kovar, J., Klakurkova, L., Bednar, J., Benes, L., \& Zahradnicek, R. (2018). Analysis of surface morphology and topography of pure aluminium machined using WEDM. Measurement, 114, 169-176.

2. Prasad, D. S., Shoba, C., Varma, K. R., \& Khurshid, A. (2015). Influence of wire EDM parameters on the damping behaviour of A356. 2 aluminum alloy. Journal of Alloys and Compounds, 646, 257-263.

3. Oberholzer, J. F., Oosthuizen, G. A., \& De Wet, P. (2017). Optimal machine parameters to maximize the accuracy of producing aluminum dovetails using WEDM. Procedia Manufacturing, 7, 472-477.

4. Soundararajan, R., Ramesh, A., Mohanraj, N., \& Parthasarathi, N. (2016). An investigation of material removal rate and surface roughness of squeeze casted A413 alloy on WEDM by multi response optimization using RSM. Journal of Alloys and Compounds, 685, 533-545.

5. Reddy, V. C., Deepthi, N., \& Jayakrishna, N. (2015). Multiple response optimization of wire EDM on aluminium HE30 by using grey relational analysis. Materials Today: Proceedings, 2(4-5), 2548-2554.

6. Bobbili, R., Madhu, V., \& Gogia, A. K. (2015). Multi response optimization of wire-EDM process parameters of ballistic grade aluminium alloy. Engineering Science and Technology, an International Journal, 18(4), 720-726.

7. Selvakumar, G., Sornalatha, G., Sarkar, S., \& Mitra, S. (2014). Experimental investigation and multi-objective optimization of wire electrical discharge machining (WEDM) of 5083 aluminum alloy. Transactions of Nonferrous Metals Society of China, 24(2), 373-379.

8. Lodhi, B. K., \& Agarwal, S. (2014). Optimization of machining parameters in WEDM of AISI D3 steel using Taguchi technique. Procedia CIRP, 14, 194-199.

9. Rao, P. S., Ramji, K., \& Satyanarayana, B. (2014). Experimental investigation and optimization of wire EDM parameters for surface roughness, MRR and white layer in machining of aluminium alloy. Procedia Materials Science, 5, 2197-2206.

10. Vanderplaats G.N. (1987) Numerical Optimization Techniques. In: Mota Soares C.A. (eds) Computer Aided Optimal Design: Structural and Mechanical Systems. NATO ASI Series (Series F: Computer and Systems Sciences), vol 27. Springer, Berlin, Heidelberg.

11. Deng, J. L. (1982). Control problems of grey systems. Sys. \& Contr. Lett., 1(5), 288-294.

12. Huang, J. T., \& Liao, Y. S. (2003). Optimization of machining parameters of wire-EDM based on grey relational and statistical analyses. International Journal of Production Research, 41(8), 1707-1720.

13. Saedon, J. B., Jaafar, N., Yahaya, M. A., Saad, N., \& Kasim, M. S. (2014). Multi-objective optimization of titanium alloy through orthogonal array and grey relational analysis in WEDM. Procedia Technology, 15, 832-840.

14. Mathew, B., \& Babu, J. (2014). Multiple process parameter optimization of WEDM on AISI304 using Taguchi grey relational analysis. Procedia Materials Science, 5, 1613-1622.

15. Khan, Z. A., Siddiquee, A. N., Khan, N. Z., Khan, U., \& Quadir, G. A. (2014). Multi response optimization of wire electrical discharge machining process parameters using Taguchi based grey relational analysis. Procedia materials science, 6, 1683-1695.

16. Durairaj, M., Sudharsun, D., \& Swamynathan, N. (2013). Analysis of process parameters in wire EDM with stainless steel using single objective Taguchi method and multi objective grey relational grade. Procedia Engineering, 64, 868-877.

17. Hicks, C. R. (1964). Fundamental concepts in the design of experiments.

18. Kuo, Y., Yang, T., \& Huang, G. W. (2008). The use of grey relational analysis in solving multiple attribute decision-making problems. Computers \& industrial engineering, 55(1), 80-93.

19. Burstein, G. T., \& Pistorius, P. C. (1995). Surface roughness and the metastable pitting of stainless steel in chloride solutions. Corrosion, 51(5), 380-385.

20. Puri, A. B., \& Bhattacharyya, B. (2005). Modeling and analysis of white layer depth in a wire-cut EDM process through response surface methodology. The International Journal of Advanced Manufacturing Technology, 25(3-4), 301-307.

21. Ho, K. H., Newman, S. T., Rahimifard, S., \& Allen, R. D. (2004). State of the art in wire electrical discharge machining (WEDM). International Journal of Machine Tools and Manufacture, 44(12-13), 1247-1259.
22. Hilbert, L. R., Bagge-Ravn, D., Kold, J., \& Gram, L. (2003). Influence of surface roughness of stainless steel on microbial adhesion and corrosion resistance. International biodeterioration \& biodegradation, 52(3), 175-185.

23. Kalsi, N. S., Sehgal, R., \& Sharma, V. S. (2013). Grey-based Taguchi analysis for optimization of multi-objective machining process in turning. International Journal of Strategic Decision Sciences (IJSDS), 4(2), 79-95.

24. http://asm.matweb.com/search/SpecificMaterial.asp?bassnum=MA70 $\underline{75 T 6}$

\section{AUTHORS PROFILE}

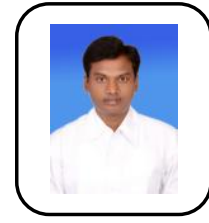

Mr.B.Rajnaveen received the B.tech degree in Mechanical Engineering from Acharya Nagarjuna University. He received the M.Tech degree in CAD/CAM, Osmania University, Hyderabad. Two years of teaching experience as Asst.Proff in MGIT, Hyd. He is Presently Research scholar in Andhra University with two publications.

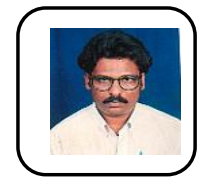

Dr G Rambabu received $\mathrm{PhD}$ from Andhra University in Department of Mechanical Engineering. He is presently working as Assistant professor in Andhra University. He has 10 National and International Publications.

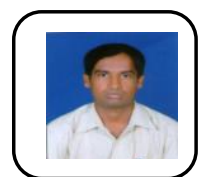

D Balaji Naik received $M$ Tech degree from Andhra University with Industrial Engineering specialization. He is presently research scholar in department of mechanical engineering, Andhra University. He has 5 International journal publications.

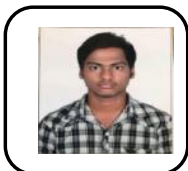

Abdul SilarBabu is M Tech scholar from Andhra University with Industrial Engineering specialization in department of mechanical engineering. 